\title{
Increased serum concentration of urinary trypsin inhibitor with asthma exacerbation
}

\author{
K. Yasui*, H. Kanda\#, T. Iwanami ${ }^{\#}$, A. Komiyama*
}

Increased serum concentration of urinary trypsin inhibitor with asthma exacerbation. K. Yasui, H. Kanda, T. Iwanami, A. Komiyama. (C) ERS Journals Ltd 2003.

ABSTRACT: The aim of the study was to determine whether the amount of urinary trypsin inhibitor (UTI) in serum, a degenerate induced by neutrophil elastase (NE), reflects the degree of bronchial inflammation in children with acute asthma exacerbation.

The involvement of neutrophil-mediated inflammation plays as important a role as eosinophil-mediated inflammation in the pathogenesis of acute asthma exacerbation. However, no measurable marker is sensitive enough to assess neutrophil-mediated inflammation in the airways. The pre- $\alpha$-linter- $\alpha$-trypsin inhibitors are assumed to be precursors of UTI. NE degrades pre- $\alpha$-linter- $\alpha$-trypsin inhibitors to liberate UTI. UTI concentrations in 25 childhood patients admitted with asthma exacerbation and 15 control subjects were measured by means of one-step sandwich-type enzyme immunoassay.

Serum UTI concentrations in the patients at admission were significantly higher than control values $\left(10.597 \pm 0.649\right.$ and $6.136 \pm 0.303 \mathrm{U} \cdot \mathrm{mL}^{-1}$, respectively (mean $\left.\pm \mathrm{SEM}\right)$ ). These levels returned to baseline values with improvement in the asthmatic symptoms. However, serum NE and $\alpha_{1}$ antitrypsin concentrations were not significantly different between patients and controls, even during acute exacerbation in the former.

The findings suggest that neutrophil-mediated inflammatory events are involved in exacerbation of childhood asthma. The monitoring of urinary trypsin inhibitor concentrations might be useful for evaluating the neutrophil-mediated inflammation in childhood asthma attack.

Eur Respir J 2003; 22: 739-742.
*Dept of Pediatrics, Shinshu University School of Medicine, Matsumoto, and ${ }^{\#}$ Dept of Pediatrics, Iiyama Red Cross Hospital, Iiyama, Japan.

Correspondence: K. Yasui, Dept of Pediatrics, Shinshu University School of Medicine, Asahi 3-1-1, Matsumoto 390-8621, Japan.

Fax: 81263373089

E-mail: k-yasui@hsp.md.shinshu-u.ac.jp

Keywords: Asthma

inflammation

neutrophil elastase

urinary trypsin inhibitor

Received: February 122003

Accepted after revision: May 122003

This work was supported by Grants-in-Aid from the Ministry of Education, Culture, Sports and Science (12670738) and from the Ministry of Health and Welfare, Japan.
Persistent inflammation in the airways is thought to be an essential feature of bronchial asthma. Histological and bronchoalveolar lavage (BAL) fluid studies have demonstrated that inflammatory cell infiltration exists in the airway even in cases of mild asthma, and that cell population increases in number during severe attacks [1, 2]. Within the last decade, the activation of neutrophils and their products have been demonstrated in the airways of patients with bronchial asthma attack [2-7]. It has been proposed that interleukin (IL)-8 and neutrophil elastase (NE) are key factors in this process [6, 8]. Neutrophils are frequently more dominant than eosinophils as the major inflammatory cells in sputa from asthmatic children during acute exacerbation and from those with asthma attack [9-11]. The presence of $\mathrm{NE}$ in fluids in the epithelial lining of the airway has been reported to induce further inflammatory cytokine release (IL8 , granulocyte-macrophage colony-stimulating) and destroy structures of the extracellular matrix and produce clinical symptoms [8, 12, 13].

$\mathrm{NE}$ is quickly inactivated by $\alpha_{1}$-antitrypsin, $\alpha_{2}$ macroglobulin, pre- $\alpha$-/inter- $\alpha$-trypsin inhibitors and anti-leukoprotease in vivo $[12,13]$. During this process, NE degrades pre- $\alpha$-/inter- $\alpha$-trypsin inhibitors to liberate urinary trypsin inhibitor (UTI), which is detectable not only in serum but also in urine $[14,15]$. The relationship between NE and pre- $\alpha$-/inter- $\alpha$-trypsin inhibitors might be similar to that between metalloproteinases induced by macrophages and tissue inhibitors of metalloproteinases by endothelium, which possibly implies that metabolites of pre- $\alpha$-/inter- $\alpha$-trypsin inhibitors (UTI) may be dominant in patients with neutrophil-mediated inflammation. Since little is known about inflammatory reactions in the airways in childhood asthma, the serum levels of UTI in children with acute asthma exacerbation were measured and compared to other proteins.

\section{Subjects and methods}

\section{Subjects}

Altogether, 25 asthmatic children, 11 female and 14 male (aged 3.4 \pm 1.5 yrs; mean $\pm \mathrm{SD}$; all aged $1-6$ yrs) were recruited from the Depts of Paediatrics at Iiyama Red Cross Hospital, Iiyama, and Shinshu Medical University Hospital, Matsumoto, Japan. Bronchial asthma was diagnosed according to the American Thoracic Society guidelines for the diagnosis of asthma [16]. The patients had been observed for $\geqslant 6$ months and some patients were treated continuously with oral theophylline after the diagnosis was made. Patients were hospitalised because of acute exacerbation of asthma attack (incomplete response to inhaled short-acting $\beta_{2}$ agonist and no improvement in oxygen saturation after continuous treatment for $2 \mathrm{~h}$ ). Initial symptoms were naturally occurring colds, and they were afebrile and none had a high level of C-reactive protein $\left(\mathrm{CRP}>2.0 \mathrm{mg} \cdot \mathrm{dL}^{-1}\right)$ or elevated peripheral neutrophil counts $(>9,000)$. In this study "atopic" was defined as an increase in serum immunoglobulin (Ig)E levels to $>250 \mathrm{IU} \cdot \mathrm{mL}^{-1}$ and $>2+$ positive for IgE radioallergosorbent test (RAST) against Dermatophagoides pteronyssinus antigen. Twelve 
patients required daily administration of oral theophylline $\left(10-16 \mathrm{mg} \cdot \mathrm{kg}^{-1} \cdot \mathrm{day}^{-1}\right)$, and of inhaled $\beta_{2}$-agonist and/or disodium chromoglycate when required. No glucocorticoid treatment was used.

\section{Controls}

The 15 controls, aged $1-6(3.5 \pm 1.2 ;$ mean \pm SD $)$ yrs, were patients at the Dept of Urology or Plastic Surgery at Iiyama Red Cross Hospital and Shinshu Medical University Hospital, who were healthy based on a physical examination and without immunological disorders and infections. None of the controls was taking medication. All the patients and controls and their parents gave informed consent to be enrolled in this study.

Assay of urinary trypsin inhibitor, neutrophil elastase, $\alpha_{1}$-antitrypsin, tissue inhibitor of metalloproteinase- 1 and matrix metalloproteinase-2

Serum UTI was determined by sandwich-type one-step enzyme immunoassay using polyclonal antibodies to human trypsin inhibitor $[14,17,18]$ and a human assay kit (Mochida Pharmaceutical Co. Ltd., Tokyo, Japan). The ELISA procedure makes it possible to specifically measure UTI by trapping pre- $\alpha$-/inter- $\alpha$-inhibitors in solid phase with a treatment of perchloric acid. Serum NE, $\alpha_{1}$-antitrypsin, tissue inhibitor of metalloproteinase-1 (TIMP-1) and matrix metalloproteinase-2 (MMP-2) concentrations were also determined with the commercially available BIOTRAK ELISA (Amersham, Little Chalfont, UK) method. UTI, $\alpha_{1}$-antitrypsin, NE, TIMP and MMP levels of all patients were measured on the day of admission, and of some patients at the time symptoms ameliorated $\geqslant 1$ week after the admission. After separation of the blood samples by centrifugation at $400 \times g$ for $10 \mathrm{~min}$ at $4^{\circ} \mathrm{C}$, serum was stored at $-30^{\circ} \mathrm{C}$.

\section{Statistical Analysis}

Results are shown as mean \pm SEM. Statistical analysis was performed using an unpaired t-test. The Pearson correlation and Fisher test were used to calculate $p$-values for correlations. Statistical significance assumed for p-values was $<0.05$.

\section{Results}

The characteristics of the 25 patients are shown in table 1 . Altogether, 12 of them had "atopic" constitution (IgE $>$ $250 \mathrm{IU} \cdot \mathrm{mL}^{-1}$ and/or $>2+$ positive for IgE RAST against $D$. pteronyssinus antigen) and another 13 had continuous treatment with a bronchodilator (theophylline). Serum UTI concentrations of the patients on admission were significantly higher than those of controls $(10.597 \pm 0.649$ versus $6.136 \pm$ $0.303 \mathrm{U} \cdot \mathrm{mL}^{-1} ; \mathrm{n}=25$ and 15 , respectively; $\mathrm{p}<0.0001$ ) (fig. 1 ). In all of the patients examined, UTI concentrations returned to baseline values when the asthmatic symptoms improved $\geqslant 1$ week after admission (fig. 2). However, there were no significant differences between the patients and controls in serum levels of NE, $\alpha_{1}$-antitrypsin, MMP-2 and TIMP-1 (fig. 3).

Serum UTI concentrations showed no correlation with peripheral blood neutrophil counts $(\mathrm{r}=0.136, \mathrm{p}=0.5213)$ nor did UTI concentrations with CRP values ( $\mathrm{r}=0.038, \mathrm{p}=0.8602$ ). In addition, there was no significant difference in serum UTI
Table 1.-Characteristics of asthmatic children with acute exacerbation

\begin{tabular}{|c|c|c|c|c|c|c|}
\hline No. & $\begin{array}{l}\text { Age } \\
\text { yrs }\end{array}$ & Sex & $\mathrm{T} / \mathrm{C}$ & Atopic & $\begin{array}{l}\text { Peripheral blood } \\
\text { neutrophils } \mu \mathrm{L}\end{array}$ & $\begin{array}{c}\mathrm{CRP} \\
\mathrm{mg} \cdot \mathrm{dL}^{-1}\end{array}$ \\
\hline 1 & 1 & $\mathrm{~F}$ & - & - & 1900 & 0.1 \\
\hline 2 & 1 & $\mathrm{~F}$ & + & - & 2950 & 0.2 \\
\hline 3 & 3 & $\mathrm{~F}$ & - & + & 1620 & 0.3 \\
\hline 4 & 3 & $\mathrm{~F}$ & + & - & 6300 & 2.0 \\
\hline 5 & 3 & $\mathrm{~F}$ & - & - & 3800 & 0.4 \\
\hline 6 & 4 & $\mathrm{~F}$ & + & + & 2650 & 0.3 \\
\hline 7 & 4 & $\mathrm{~F}$ & + & - & 3500 & 0.3 \\
\hline 8 & 4 & $\mathrm{~F}$ & + & + & 4180 & 0.5 \\
\hline 9 & 5 & $\mathrm{~F}$ & - & + & 4000 & 0.2 \\
\hline 10 & 6 & $\mathrm{~F}$ & - & - & 2620 & 0.8 \\
\hline 11 & 6 & $\mathrm{~F}$ & - & + & 4900 & 0.7 \\
\hline 12 & 1 & M & - & - & 8500 & 1.8 \\
\hline 13 & 2 & M & + & - & 8190 & 0.3 \\
\hline 14 & 2 & M & - & + & 6800 & 1.6 \\
\hline 15 & 2 & M & - & - & 2800 & 0.3 \\
\hline 16 & 3 & $\mathrm{M}$ & + & + & 3750 & 0.4 \\
\hline 17 & 3 & M & + & + & 7600 & 0.2 \\
\hline 18 & 3 & M & + & + & 4040 & 0.2 \\
\hline 19 & 3 & $\mathrm{M}$ & + & + & 5450 & 0.1 \\
\hline 20 & 3 & $\mathrm{M}$ & + & - & 5270 & 1.5 \\
\hline 21 & 3 & $\mathrm{M}$ & - & - & 4100 & 0.7 \\
\hline 22 & 4 & $\mathrm{M}$ & - & - & 7700 & 1.3 \\
\hline 23 & 5 & $\mathrm{M}$ & + & + & 7200 & 0.2 \\
\hline 24 & 5 & M & - & + & 3640 & 0.2 \\
\hline 25 & 6 & M & + & - & 3380 & 0.0 \\
\hline Mean \pm SD & $3.4 \pm 1.5$ & & & & $4673 \pm 1983$ & $0.58 \pm 0.57$ \\
\hline
\end{tabular}

T/C: Continuous treatment with a bronchodilator; Atopic: serum immunoglobulin E (IgE) increase $>250 \mathrm{IU} \cdot \mathrm{mL}^{-1}$ and $>2+$ positive for IgE radiallergosorbent test against Dermatophagoides pteronyssinus antigen; CRP: C reactive protein; F: female; M: male; +: positive; -: negative.

levels between the "atopic" and "nonatopic" patients (10.572 \pm 1.135 to $10.616 \pm 0.782, \mathrm{p}=0.9744)$.

\section{Discussion}

There is increasing evidence that neutrophils are involved in acute asthma exacerbation. Prominent neutrophilic inflammation has been demonstrated during exacerbated asthma

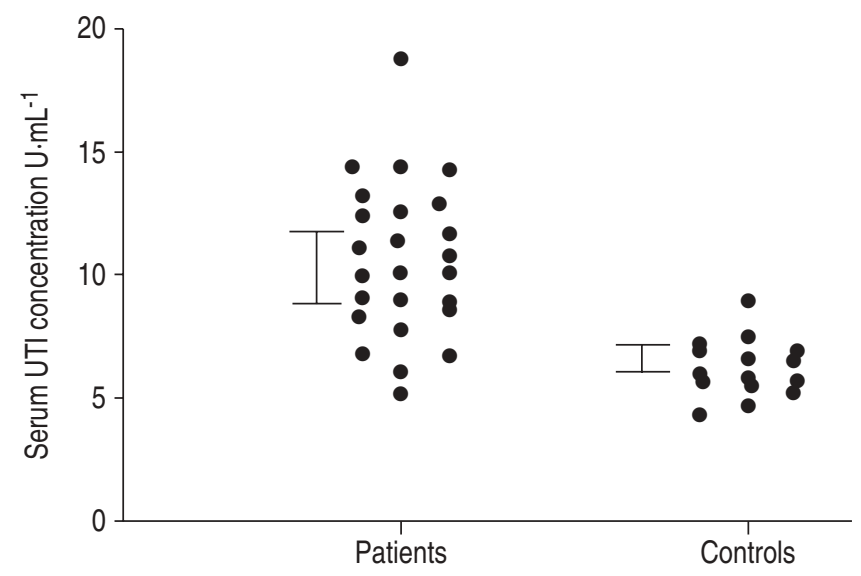

Fig. 1.-Serum concentrations of urinary trypsin inhibitor (UTI) in childhood asthma with acute exacerbation. Comparison with agematched controls is shown. Vertical bars show mean \pm SEM. $\mathrm{p}<0.0001$. $\mathrm{n}=25$ (patients) and 15 (controls). 


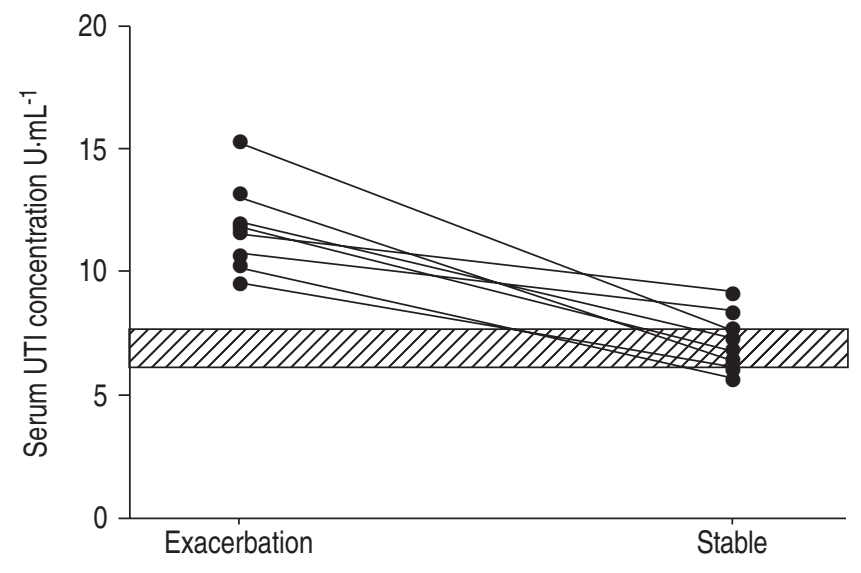

Fig. 2.-Serum concentrations of urinary trypsin inhibitor (UTI) in asthmatic patients. Exacerbation: during asthma exacerbation; Stable: improvement of asthmatic symptoms. $\mathbb{Z}:$ mean \pm SEM of control values. $\mathrm{n}=8$.

in adult patients [2-8]. Recently, inflammatory profiles of asthmatic airways in children have been assessed by analysing sputum and/or BAL fluid [9-11]. These studies proposed that neutrophil-mediated inflammation was also involved in the pathophysiology of exacerbation of childhood asthma. However, the nature of airway inflammation in childhood asthma and its severity have not been adequately evaluated because bronchoscopic studies or BAL fluid analysis can be too invasive for children.
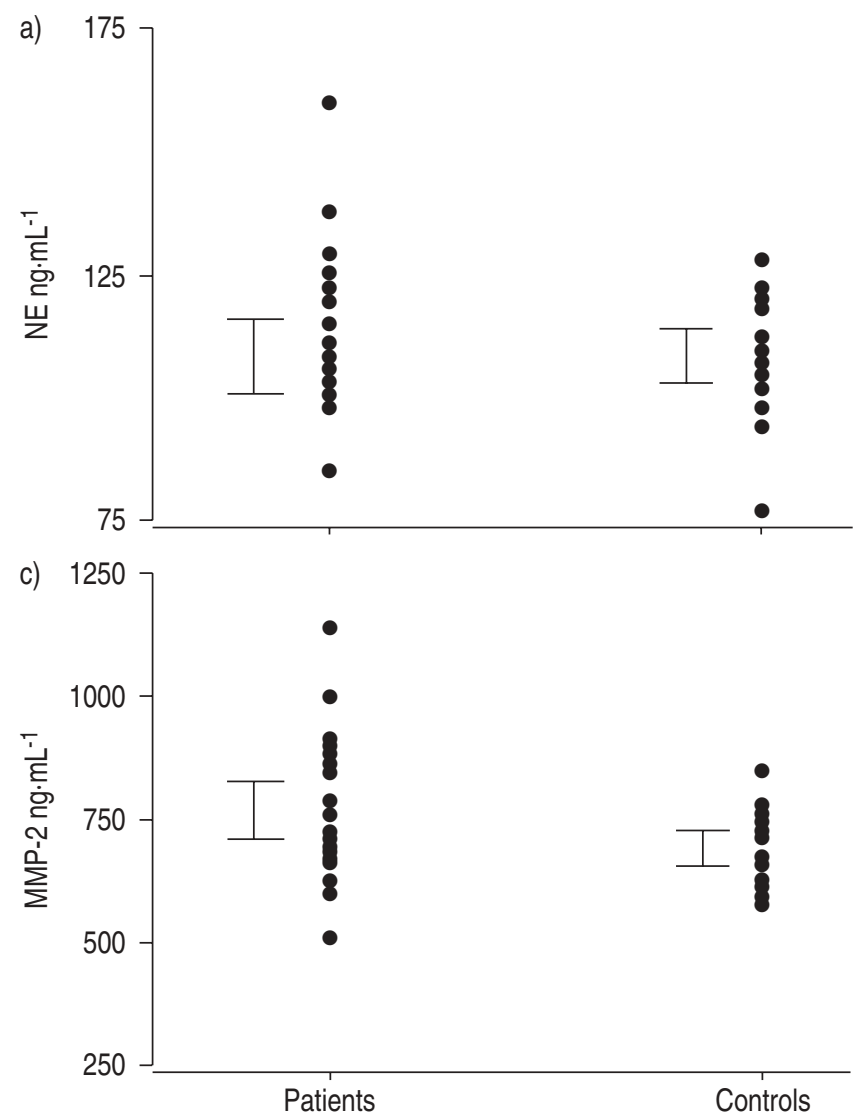

There are several lines of evidence that activation of $\mathrm{NE}$ is involved in asthma exacerbation and results in hypersecretion by mucous-producing cells $[8,12,13]$. In BAL fluid of asthmatic subjects, excessive secretion of proteinases, including NE and MMPs, has been observed during acute asthma exacerbation [12, 19]. However, it is hard to detect elevated NE levels in blood, because NE is quickly inactivated and complexed to $\alpha_{1}$ antitrypsin in vivo $[14,15]$. This may explain why the authors were unable to find any difference in the serum levels of NE or $\alpha_{1}$ antitrypsin of patients and controls. Several proteins are known to inactivate NE activity and NE degrades the pre- $\alpha$-/inter- $\alpha$-trypsin inhibitors, proteinase inhibitors, that release UTI $[14,15]$. UTI has been reported to be a positive acute phase protein whose concentration in serum and excretion in urine is increased in proportion to the invasiveness of the various diseases and the activation of neutrophils [17, 18]. Previous study showed that both NE and UTI concentrations in BAL fluid of acute respiratory distress syndrome are significantly elevated, but only UTI concentration is significantly high in the serum [20]. In the present study, serum UTI concentrations during asthma exacerbation in children were observed to be significantly higher than that in controls and that the UTI concentrations returned to normal after remission had been attained. Sputum levels of the cytokine IL-8 are known to correlate with neutrophil counts in sputum $[3,9]$, which in turn may correlate with NE levels in BAL [3]. Neutrophils are mobilised and the elevated UTI concentrations were observed in bacterial pneumonia $[17,18]$. In the current study, neither peripheral blood neutrophil counts nor CRP values showed a significant correlation with serum UTI concentrations. The results suggest
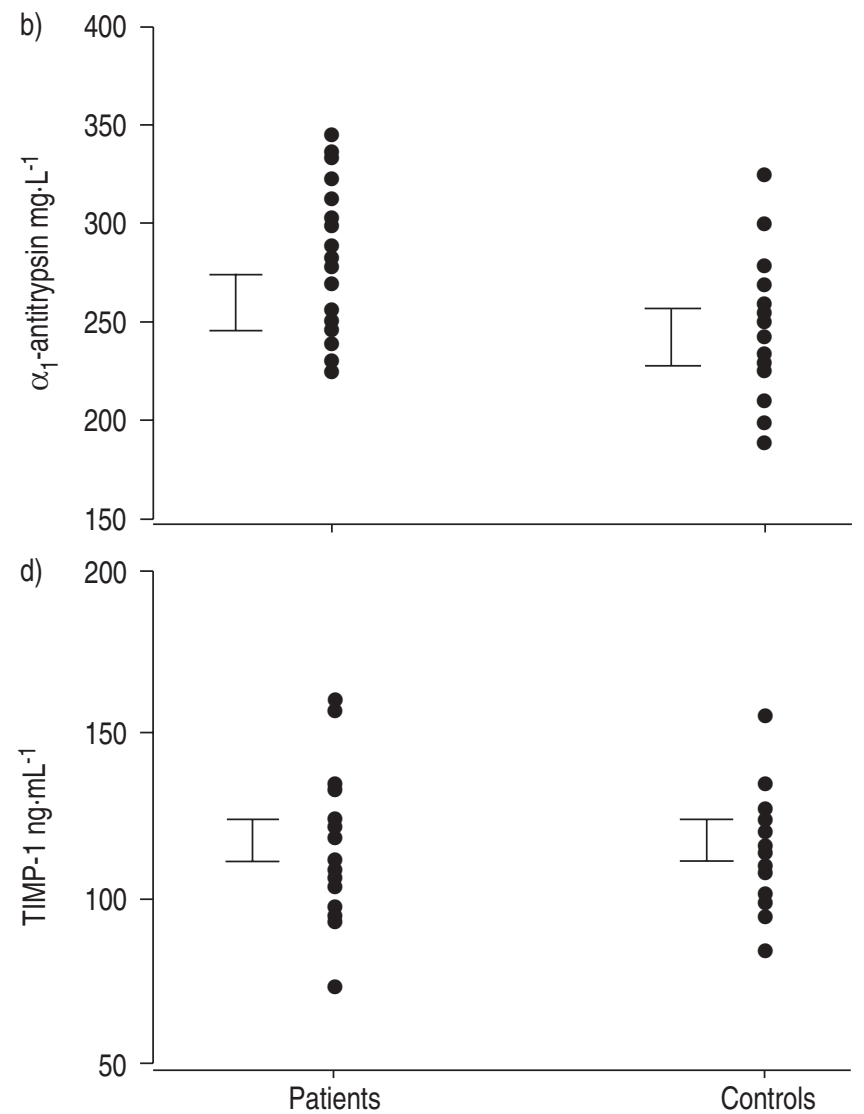

Fig. 3. - Serum concentrations of a) neutrophil elastase (NE) ( $\mathrm{p}=0.6340)$, b) $\alpha_{1}$-antitrypsin ( $\left.\mathrm{p}=0.5002\right)$, c) matrix metalloproteinase-2 (MMP-2) $(\mathrm{p}=0.0923)$ and $\mathrm{d})$ tissue inhibitor of metalloproteinase-1 (TIMP-1) $(\mathrm{p}=0.9967)$ in childhood asthma with acute exacerbation. Comparison with age-matched controls is shown. Vertical bars show mean \pm SEM. $n=25$ (patients) and 15 (controls). 
that the activation of neutrophils is involved in the pathogenesis of asthma exacerbation in children, regardless of peripheral neutrophil counts or bacterial infections.

Although MMPs, TIMP-1 are elevated in the sputum or BAL fluid of asthmatic patients [19,21]. The authors were unable to find any significant differences in the serum levels of these enzymes. It is thought that these proteins might be secreted and mutually inactivated in localised areas, as well as NE. If this is the case, it is not likely that their elevation in serum is detectable. Compared to these proteins, UTI appear to be more stable, because the activity of this protein is detectable in serum or urine $[14,15]$.

In asthma, so far, no marker is sensitive enough to assess neutrophil-mediated inflammation in airways that can be measured in the urine or in the blood. Urinary trypsin inhibitor concentrations have already attracted attention as a useful index of the status of systemic inflammatory response syndrome [14, 17, 18]. It has been reported that neutrophil activation and cell infiltration develop in childhood asthmatic patients even in viral infections $[7,9,11]$. The current study confirms that neutrophil-mediated inflammatory events are involved in the exacerbation of childhood asthma and that the inflammation exerts some influence in the airway even in the absence of bacterial infections. The monitoring of urinary trypsin inhibitor concentrations might be useful, in part at least, for evaluating the neutrophil-mediated inflammation in asthma attack. Furthermore, the findings may provide some important information related to the treatment of asthma exacerbation. The administration of theophylline and/ or aminophylline (bronchodilators) for the treatment of asthma exacerbation have been used empirically with unproven clinical benefit. These drugs not only dilate the larger and medium bronchi but modulate neutrophil functions [22-25] and thus may suppress neutrophil-mediated inflammation in virus-induced asthma exacerbation in children.

\section{References}

1. Djukanovic R, Roche WR, Wilson JW, et al. Mucosal inflammation in asthma. Am Rev Respir Dis 1990; 142: 434 457.

2. Sur S, Crotty TB, Kephart GM, et al. Sudden-onset fatal asthma - A distinct entity with few eosinophils and relatively more neutrophils in the airway submucosa? Am Rev Respir Dis 1993; 148: 713-719.

3. Fahy JV, Kim KW, Liu J, Boushey HA. Prominent neutrophilic inflammation in sputum from subjects with asthma exacerbation. J Allergy Clin Immunol 1995; 95: 843852.

4. Lamblin C, Gosset P, Tille-Leblond I, et al. Bronchial neutrophilia in patients with noninfectious asthmaticus. $\mathrm{Am}$ J Respir Crit Care Med 1998; 157: 394-402.

5. Jatakanon A, Uasuf C, Maziak W, Lim S, Chung KF, Barnes PJ. Neutrophilic inflammation in severe persistent asthma. Am J Respir Crit Care Med 1999; 160: 1532-1539.

6. Ordonez CL, Shaughnessy TE, Matthay MA, Fahy JV. Increased neutrophil numbers and IL-8 levels in airway secretions in acute severe asthma. Am J Respir Crit Care Med 2000; 161: 1185-1190.

7. Wark PAB, Johnston SL, Moric I, Simpson JL, Hensley MJ, Gibson PG. Neutrophil degranulation and cell lysis is associated with clinical severity in virus-induced asthma. Eur Respir $J$ 2002; 19: 68-75.

8. Nadel JA, Takeyama K, Agusti C. Role of neutrophil elastase in hypersecretion in asthma. Eur Respir J 1999; 13: 190-196.

9. Teran LM, Johnston SL, Schroder J-M, Church MK, Holgate ST. Role of nasal interleukin-8 in neutrophil recruitment and activation in children with virus-induced asthma. Am J Respir Crit Care Med 1997; 155: 1362-1366.

10. Marguet C, Jouen-Boedes F, Dean TP, Warner JO Bronchoalveolar cell profiles in children with asthma, infantile wheeze, chronic cough, or cystic fibrosis. $\mathrm{Am} \mathrm{J}$ Respir Crit Care Med 1999; 159: 1533-1540.

11. Norzila MZ, Fakes K, Henry RL, Simpson J, Gibson PG. Interleukin-8 secretion and neutrophil recruitment accompanies induced sputum eosinophil activation in children with acute asthma. Am J Respir Crit Care Med 2000; 161: 769-774.

12. Gadek JE, Kelman JA, Fells G, et al. Collagenase in the lower respiratory tract of patients with idiopathic pulmonary fibrosis. N Engl J Med 1979; 301: 737-742.

13. Nakamura $\mathrm{H}$, Abe $\mathrm{S}$, Shibata $\mathrm{Y}$, et al. Inhibition of neutrophil elastase-induced interleukin- 8 gene expression by urinary tripsin inhibitor in human bronchial epithelial cells. Int Arch Allergy Immunol 1997; 112: 157-162.

14. Yamada S, Takatsuka H, Takemoto Y, et al. Urinary trypsin inhibitor concentration can predict the immunological insult of chemotherapy and complications after bone marrow transplantation. Bone Marrow Transplant 2001; 27: 195-199.

15. Hirose J, Ozawa T, Miura T, et al. Human neutrophil elastase degrades inter- $\alpha$-trypsin inhibitor to liberate urinary trypsin inhibitor related proteins. Biol Pharm Bull 1998; 21: 651-656.

16. American Thoracic Society. Standards for the diagnosis and care of patients with chronic obstructive pulmonary disease (COPD) and asthma. Am Rev Respir Dis 1987; 136: 225-244.

17. Pugia MJ, Takemura T, Kuwajima S, et al. Clinical utility of a rapid test for uristatin. Clin Biochem 2002; 32: 105-110.

18. Mizon C, Piva F, Queyrel V, Balduyck M, Hachulla E, Mizon J. Urinary bikunin determination provides insight into proteinase/proteinase inhibitor imbalance in patients with inflammatory diseases. Clin Chem Lab Med 2002; 40: 579-586.

19. Mautino G, Oliver N, Chanez P, Bousquet J, Capony F. Increased release of matrixmetalloproteinase- 9 in bronchoalveolar lavage fluid and by alveolar macrophages of asthmatics. Am J Respir Cell Mol Biol 1997; 17: 583-691.

20. Nakane $\mathbf{M}$, Iwama $\mathbf{H}$. Intra-alveolar urinary trypsin inhibitor cannot inhibit polymorphonuclear elastase activity in the lung in postsurgical patients with acute respiratory distrea syndrome. Surg Today 1999; 29: 1030-1033.

21. Mautino G, Henriquet C, Jaffuel D, Bousquet J, Capony F. Tissue inhibitor of metalloproteinase-1 levels in bronchoalveolar lavage fluid from asthmatic subjects. Am J Respir Crit Care Med 1999; 160: 324-330.

22. Llewellyn-Jones CG, Stockley RA. The effects of beta 2-agonists and methylxanthines on neutrophil function in vitro. Eur Respir J 1994; 7: 1460-1466.

23. Kraft M, Pak J, Borish L, Martin RJ. Theophylline's effect on neutrophil function and the late asthmatic response. J Allergy Clin Immunol 1996; 98: 251-257.

24. Yasui K, Hu B, Nakazawa T, Agematsu K, Komiyama A Theophylline accelerates human granulocyte apoptosis not via phosphodiesterase inhibition. J Clin Invest 1997; 100: 1677-1684.

25. Yasui K, Agematsu K, Shinozaki K, et al. Effects of theophylline on human eosinophil functions: comparative study with neutrophil functions. J Leukoc Biol 2000; 68: 194 200. 